\title{
GLOBALIZAÇÃO E URBANIZAÇÃO SUBDESENVOLVIDA
}

\author{
João Sette Whitaker Ferreira \\ Professor de Planejamento Urbano \\ Pesquisador do Laboratório de Habitação e Assentamentos Humanos da FAUUSP
}

\begin{abstract}
Resumo: O presente artigo discute as relações entre o novo paradigma econômico da globalização e a urbanização acelerada das grandes metrópoles subdesenvolvidas. Baseando-se em dados estatísticos, ressalta-se o extremo grau de pobreza comum a todas essas cidades da periferia da economia-mundo capitalista. Analisase, por fim, o caráter das novas matrizes de planejamento urbano relacionadas à globalização, questionando sua eficácia no combate aos determinantes estruturais da pobreza urbana.

Palavras-chave: cidades-globais; globalização; urbanização da pobreza.
\end{abstract}

$\mathrm{E}$ ste artigo inicia-se mencionando a história recente de uma grande metrópole subdesenvolvida. Principal cidade de seu país, abrigando $55 \%$ das riquezas, foi objeto de um fantástico movimento de investimentos internacionais, que se intensificou a partir da década de 90 graças à liberalização de sua economia. Como resultado, os bairros com maior acessibilidade viária viram crescer mais de mil edifícios ultramodernos, torres inteligentes com mais de 50 andares, oferecendo escritórios com toda a infra-estrutura demandada pelas grandes corporações internacionais e pelos serviços ligados ao chamado "terciário avançado", ou ainda residências com o alto padrão exigido pelos homens de negócios globalizados. Em outras palavras, essa cidade seguiu a receita do urbanismo da pós-modernidade, que alguns chamam de Planejamento Estratégico. Inseriu-se, no circuito das "cidadesglobais", esse arquipélago de competitividade urbana internacional, no qual a cidade é uma "máquina de produzir renda", uma mercadoria em potencial que conseguirá atrair tanto mais investimentos quanto souber aproveitar as "possibilidades" econômicas do espaço urbano, através da coalizão entre as elites fundiárias, o poder público e os empreendedores imobiliários (Arantes et alii, 2000; Vainer, 2000). ${ }^{1}$

Poder-se-ia afirmar que o quadro anteriormente descrito refere-se à cidade de São Paulo. Entretanto, e apesar das semelhanças, trata-se de Bangcoc, capital da Tailândia, uma metrópole de cerca de 8,5 milhões de habitantes (na região metropolitana, em 1990). E a continuação da história não é propriamente uma novela de sucesso, pois atribui-se justamente à "bolha especulativa imobiliária" que ali se criou a gênese da crise financeira que assolou o mundo em 1998, lembrada nas nossas memórias como a "crise asiática". Vejamos exatamente o que ocorreu, e porque esse acontecimento reflete um modelo de urbanismo globalizado que se repete na maioria das metrópoles subdesenvolvidas, inclusive em São Paulo.

\section{A "BOLHA ESPECULATIVA" TAILANDESA}

Desde 1985, a Tailândia já vinha recebendo, devido a uma conjuntura cambial favorável, à oferta de mãode-obra barata e a uma relativa estabilidade política, investimentos japoneses diretos que lhe permitiram lograr um crescimento econômico significativo até o final da década (Charmes, 1998). No início dos anos 90, sob os novos ventos da economia mundial e acuada por fortes pressões internacionais, a Tailândia adotou (assim como o Brasil e muitos outros países subdesenvolvidos) a receita econômica neoliberal, visando atrair, por meio da desregulação financeira, da abertura do mercado e da elevação das taxas de juros, o seu quinhão do enorme volume de capital financeiro internacional que até hoje perambula pelo mundo. 
Do ponto de vista urbano, as conseqüências dessa dinamização econômica foram imediatas na cidade de Bangcoc. Segundo o pesquisador francês Eric Charmes (1998), a produção anual de escritórios chegou a mais de um milhão de metros quadrados em 1994 e a de apartamentos residenciais, a mais de 150 mil unidades. ${ }^{2}$ Imensos empreendimentos residenciais de alto luxo foram lançados nas cercanias do centro bem servidas pela rede viária (a exemplo do paulistano Village Pananby, às margens do rio Pinheiros) e, em 1995, iniciou-se a construção da mais alta torre em concreto do mundo, a Baiyoke Tower II, com 320 metros de altura e 90 andares. A valorização imobiliária insuflou-se (o preço total das residências à venda na cidade, em 1994, chegou a 5 bilhões de dólares) e o valor da terra multiplicou-se exponencialmente, chegando a 5 mil dólares o metro quadrado de terreno nas áreas mais valorizadas. Assim, somente empreendimentos de grande porte poderiam ser rentáveis, o que favoreceu a presença, por detrás dessas operações, dos fundos de pensão internacionais e de empreiteiras globalizadas, como a gigante francesa Bouygues. Em mercados razoavelmente organizados e regrados (o que não ocorre no Brasil, neste setor), os investimentos imobiliários podem ser altamente rentáveis, apesar de serem considerados de alto risco diante da imobilidade do capital investido. Por isso, verifica-se a ocorrência, não só na Tailândia, mas também em HongKong e no Japão, de forte atividade no setor através de grandes empreendimentos gerenciados - no caso dos edifícios comerciais - como empresas anônimas com cotas de participação (e não se vendendo escritórios um a um).

Porém, apesar de toda a euforia econômica e imobiliária, a Tailândia nunca deixou de ser um país subdesenvolvido e, como tal, nunca deixou de ter pobres, aliás em maioria absoluta. Assim, ainda segundo Charmes (1998), somente $10 \%$ das famílias de Bangcoc tinham condições, em 1995, de adquirir moradias vendidas a preços acima de 48 mil dólares (cerca de $30 \%$ da oferta). As estimativas mais otimistas apontavam, no mesmo ano, que cerca de 275 mil famílias moravam em favelas ou habitações informais. Rapidamente, verificou-se que a festejada oferta de habitações e escritórios comerciais estava muito acima da demanda real, o que provocou, já em 1995, a vacância de $30 \%$ dos imóveis ofertados.

A política econômica baseada na estagnação da indústria e das exportações e na explosão das importações e do consumo provocou, concomitantemente, um endividamento que obrigou o governo a tomar atitudes recessivas e restritivas, em especial quanto aos empreendimentos imobiliários. A impopularidade gerada levou à sua substituição, em 1995, por outro governo comprometido com os interesses dos setores financeiro e imobiliário, que acentuou a crise ao reforçar a liberalização econômica, investir em mega-obras viárias próximas aos grandes projetos imobiliários e pôr em prática programas de salvamento das instituições financeiras e imobiliárias falidas (Charmes, 1998), aliás muito parecidos com o nosso Proer.

Junto a isso, e como último recurso em face da crise que se apresentava para alavancar os fundos necessários a seus empreendimentos, 36 empresas de promoção imobiliária lançaram ações na Bolsa de Valores. Em 1996, $61 \%$ da capitalização na bolsa de Bangcoc devia-se a títulos vendidos por essas empresas e por instituições financeiras ligadas à promoção imobiliária. Assim, as dificuldades vividas por esse setor rapidamente causaram a queda da bolsa de Bangcoc, gerando desconfiança internacional. Em 1997, quando a Somprasong Land, uma das maiores empresas imobiliárias do país, anunciou sua incapacidade em pagar obrigações contraídas no mercado internacional, iniciou-se um movimento de fuga maciça de capitais, desestabilizando de vez a economia do país, obrigado a recorrer à ajuda do FMI. A crise asiática estava deflagrada, e seu efeito dominó sobre o mercado financeiro mundial chegaria rapidamente por aqui.

O relato das conseqüências da chamada "bolha especulativa" tailandesa, aqui resumidas a partir do elucidativo artigo de Eric Charmes (1998), serve para mostrar uma situação que encontra similitudes por todos os cantos do Hemisfério Sul: a intrínseca relação causaefeito estabelecida entre políticas econômicas de ajuste estrutural de cunho liberal, adotadas por diversas economias dependentes segundo os moldes preconizados pelas agências multilaterais, e a manutenção - quando não o agravamento - da trágica situação socioeconômica da maior parte da população desses países. No âmbito das grandes metrópoles, isso se traduz por um crescimento da população excluída vivendo em condições de absoluta pobreza. Em outras palavras, o que aconteceu em Bangcoc é sintomático e familiar em qualquer país subdesenvolvido: a aguda contradição entre a globalização "modernizadora" empreendida pelas elites dominantes, ideologicamente apresentada como um passaporte de ingresso para o Primeiro Mundo, e as bases sociais miseráveis, oriundas do passado colonial, sobre as quais essa modernização se assenta de maneira ainda mais acentuada nas grandes metrópoles urbanizadas do Terceiro Mundo. 


\section{DESENVOLVIMENTO DESIGUAL E COMBINADO}

Tal contradição não é nova e foi há muito evidenciada pelos grandes intérpretes da formação do Brasil, como Caio Prado Jr., Florestan Fernandes e Celso Furtado. Embora suas análises se ancorem intimamente na realidade das sociedades latino-americanas, elas descrevem uma lógica comum, em muitos aspectos, a todos os países que vivem sob a égide do capitalismo dependente. ${ }^{3}$ Estes autores ressaltam a oposição entre imperialismo (os interesses da expansão da economia-mundo capitalista ${ }^{4}$ ) e formação de Estados Nacionais capazes de controlar o próprio destino (Sampaio Jr., 1999a). Tal oposição se manifesta na impossibilidade de compatibilizar desenvolvimento capitalista, democracia e soberania nacional.

No Brasil, a aliança estratégica da burguesia com o capital internacional e com as potências hegemônicas permitiu que a industrialização por substituição de importações fosse levada às últimas conseqüências, aumentando o grau de autonomia relativa do país dentro do sistema capitalista mundial (Sampaio Jr., 1999b). Em outros países periféricos, a ausência de uma indústria nacional minimamente significativa relegou às elites um papel de simples coadjuvante interno dos agentes do comércio internacional, o que foi denominado, pelo sociólogo egípcio Samir Amin (1991), de "compradorização" das elites subdesenvolvidas. O impacto extremamente destrutivo da globalização sobre o parque industrial brasileiro, ao ameaçar a continuidade do processo de industrialização, parece relegar nossa burguesia ao mesmo papel de mera "compradora" dentro do sistema capitalista mundial. Entretanto, o que se quer destacar aqui é o processo pelo qual a burguesia "moderna" garante seus interesses de hegemonia interna, sobrepondo-se às elites mais conservadoras ("atrasadas") e promovendo o avanço capitalista internacional por sobre uma estrutura social arcaica baseada em relações de desigualdade e dominação herdadas do Brasil colonial. Essa é a estrutura do que muitos autores brasileiros, e Florestan Fernandes em especial, chamaram de desenvolvimento desigual - em relação ao desenvolvimento do capitalismo hegemônico dos países industrializados, e combinado -, pois dispõe novas estruturas econômicas e sociais trazidas do centro sobre estruturas internas arcaicas (Sampaio Jr., 1999a).

O entendimento dos autores citados anteriormente é de que a contradição entre desenvolvimento desigual do capitalismo em escala mundial e o processo de formação do
Brasil não se esgotou. Ao contrário, Sampaio Jr. (1999a e b) avalia que esta contradição transformou-se hoje em aberto antagonismo, ou seja, uma relação pela qual a possibilidade de controle da sociedade sobre seu próprio destino não é mais compatível com a manutenção de suas assimetrias sociais e sua posição subalterna e dependente em relação à economia-mundo capitalista. O dilema imposto por tal impasse e as conseqüências decorrentes de uma ou outra opção levam o autor a afirmar que o Brasil encontra-se hoje "entre a Nação e a Barbárie" (Sampaio Jr., 1999c:12). Não obstante, é nesse cenário de antagonismo que se insere o discurso da globalização, incorporado pelas burguesias "modernas" como o instrumento mais apropriado, no novo contexto histórico do capitalismo financeiro, para perpetuar uma nova imposição de incorporação dos progressos técnicos do capitalismo hegemônico, que somente à elite beneficiarão e lhe garantirão a manutenção de sua hegemonia interna.

\section{URBANIZAÇÃO DA POBREZA}

As grandes metrópoles subdesenvolvidas são hoje a expressão do antagonismo e da desigualdade anteriormente descritos. Em primeiro lugar, porque o fenômeno de urbanização acelerada observado no mundo nos últimos 40 anos ocorreu, em grande parte, nos países da periferia do sistema. Em segundo lugar, porque, uma vez isto posto, observa-se que são justamente as cidades os instrumentos de excelência do fenômeno de expansão da economiamundo capitalista que se convencionou a chamar de globalização. Sedes de grandes corporações transnacionais e de instituições financeiras, redes de informação, teleportos e sistemas de telefonia celular e de comunicação por cabo, bens de consumo sofisticados e atividades de serviços são elementos da "modernidade" associada à globalização. Elementos de caráter essencialmente urbano, a tal ponto que servem de parâmetro de definição das "cidades-globais" para os autores que se empenham nesse tipo de caracterização (Sassen, 1996; Borja e Castells, 1997a).

O fenômeno de urbanização observado em grande parte dos países subdesenvolvidos em muito se deve à matriz de industrialização tardia da periferia. A atratividade exercida pelos pólos industriais sobre a massa de mãode-obra expulsa do campo (em especial nos países que receberam empresas multinacionais que alavancaram a passagem de economias agroexportadoras para economias "semi-industrializadas", 5 como o Brasil ou a Índia) provocou, a partir da década de 60, a explosão de grandes 
pólos urbanos no Terceiro Mundo, que não receberam a provisão de habitações, infra-estrutura e equipamentos urbanos que garantisse qualidade de vida a essa população recém-chegada. Na maioria dos casos, o poder público pouco se empenhou para isso, devido à abundância de mãode-obra ofertada (que reduzia seu poder de reivindicação) e à sua imiscuição com as elites dominantes, interessadas em manter baixos os níveis salariais e o custo da mão-deobra. O resultado desse processo - que chamaremos de "urbanização desigual" - são as gigantescas metrópoles industriais fordistas subdesenvolvidas, concentradoras da produção industrial e da massa de mão-de-obra disponível e marcadas pela divisão social do espaço urbano, que Lipietz (1985) chamou de "aglomerações paternalistas", típicas do "fordismo periférico". Segundo Sampaio Jr. (1999b:425), já na década de 70 Caio Prado Jr. vislumbrava o caráter excludente dessa forma de urbanização: "a inexorável desarticulação da industrialização agravaria de maneira gigantesca o excedente estrutural de mãode-obra, o qual, pela sua magnitude absoluta e pela sua elevada concentração nos centros urbanos, tenderia a tornar cada vez mais difícil e traumática a sua posterior integração no desenvolvimento capitalista, agravando ainda mais a crise social." (grifo meu).

É importante ressaltar que as taxas de urbanização elevadíssimas da América Latina (média de 75\% em 2000, segundo a Cepal) não encontram equivalência na Ásia ou na África, onde a população ainda é predominantemente rural. ${ }^{6}$ Entretanto, isso não desmente a observação do forte ritmo de urbanização do Terceiro Mundo, já que, não obstante suas baixas taxas de urbanização, esses continentes apresentam grande número de metrópoles que, isoladamente, ultrapassam os 5 milhões de habitantes e organizam-se segundo as características da aglomeração fordista periférica. Observa-se que, entre as dez áreas metropolitanas mais populosas do mundo, apenas três (Tóquio, Nova York e Osaka) são do Norte e as outras sete pertencem a países subdesenvolvidos ${ }^{7}$ (dessas sete, só três estão na América Latina).

Essas grandes aglomerações urbanas da periferia, justamente em virtude dessa urbanização desigual, apresentam hoje, invariavelmente, um absoluto quadro de pobreza. Ermínia Maricato mostra, em artigo nessa mesma revista, que o processo de urbanização permitiu, é verdade, melhorias significativas em alguns indicadores sociais, principalmente nos demográficos. A América Latina, e em especial o Brasil, apresentou melhorias nos índices de esperança de vida ao nascer, ou ainda na taxa de mortalidade infantil, em grande parte conseqüência do aumento da infra-estrutura urbana básica ofertada (saneamento, água tratada, etc.). Dados da Cepal mostram que na América Latina, em virtude de sua alta taxa de urbanização, predomina a pobreza econômica (devido aos baixos salários) sobre aquela por falta de infra-estrutura básica adequada. Se em 1980 as carências físicas (necessidades básicas não-satisfeitas) superavam em porcentagem a incidência de pobreza $(54 \%$ e $35 \%$, respectivamente), já em 1997 essa relação havia se invertido, com o índice de pobreza somando $36 \%$, contra $32 \%$ da população sem saneamento básico (Arriagada, 2000:11).

Em contrapartida, Maricato mostra que a urbanização desigual provocou também uma piora nos índices socioeconômicos (crescimento, renda, desemprego e violência) e urbanísticos (crescimento urbano e aumento de favelas). O que se verifica é que a urbanização é, de fato, concentradora da pobreza. Ainda segundo Arriagada (2000), 60\% dos pobres da América Latina moram em zonas urbanas, "situação que converte o continente na região em desenvolvimento que melhor exemplifica o processo mundial de 'urbanização da pobreza" (Arriagada, 2000:8, grifos meus). Na virada do século, 125,8 milhões de moradores de áreas urbanas do continente são pobres. A ONU define como pobre a pessoa que ganha menos de 400 dólares por ano. ${ }^{8}$ Ainda segundo a Cepal, na América Latina, cerca de 220 milhões de pessoas viviam na pobreza no ano 2000, o que representa aproximadamente $45 \%$ da população do continente (Cepal, 2000a). No mundo, esse número se eleva a 1,3 bilhão de pessoas, ou um quinto da população mundial (Ibase, 1997), boa parte concentrada nas grandes metrópoles da periferia.

As condições de pobreza encontradas nessas cidades podem ser verificadas pela alta porcentagem de moradores vivendo em habitações subnormais. No Brasil, entende-se por esse termo moradias em favelas, cortiços e loteamentos clandestinos. A informalidade urbana diz respeito à inadequação físico-construtiva da habitação e/ ou geomorfológica/ambiental do entorno (construções precárias, terrenos em áreas de risco ou de preservação ambiental, área útil insuficiente para o número de moradores, etc.), à ausência de infra-estrutura urbana (saneamento, água tratada, luz, acessibilidade viária, etc.), ou ainda à ilegalidade da posse da terra ou do contrato de uso. Dentro dessas características, variam de idioma para idioma os termos que designam tais habitações: villas, callampas, barriadas, tomas, slums, bidonvilles, etc. (Clichevsky, 2000). O que não variam são o grau de precariedade e a 
falta de qualidade, características da globalização da pobreza.

Nas grandes metrópoles brasileiras, estima-se que cerca de $50 \%$ da população, em média, resida na informalidade, o que só em São Paulo representa cerca de 6 milhões de pessoas. Os moradores de favelas chegam a cerca de $20 \%$ da população dessa cidade, assim como em Porto Alegre, Belo Horizonte e Rio de Janeiro, chegando a 46\% em Recife (Bueno apud Clichevsky, 2000). Em Córdoba, na Argentina, cerca de $20 \%$ da população mora em favelas (villas) (Luciano, 1997) e na região metropolitana de Lima (Peru), 50\% dos habitantes moram em condições subnormais, sendo $30 \%$ em favelas e $20 \%$ em cortiços (Castro e Riofrío, 1997). Esse número se repete em Quito e em Caracas, no Equador, atingindo 59\% na Cidade do México e em Bogotá (Cepal, 2000b). Tal situação não se restringe às metrópoles latino-americanas. Uma rápida "volta ao mundo" mostra como pobreza e urbanização formam um par bastante globalizado, apresentando números incrivelmente semelhantes. Em 1996, estimavase que $50 \%$ da população de Deli, na Índia, morava informalmente (Bueno, 2000), sendo $25 \%$ em favelas (IRD, 1998). Em Bombaim, no mesmo país, estimava-se em 150 mil o número de moradores de rua, sendo que, em 1991, $45 \%$ da população vivia em assentamentos ilegais (Bueno, 2000). Chittagong, a segunda maior cidade de Bangladesh, tem uma população estimada entre 1,5 e 2,5 milhões de habitantes, dos quais 1 milhão são favelados (FPH, 1997). Nas Filipinas, Manila apresentava, também em 1996, 40\% de sua população residindo na informalidade, porcentagem próxima à de Karachi, no Paquistão (44\%, em 1996) (Bueno, 2000). Já na Indonésia, em 1994, essa porcentagem subia para $70 \%$, nas cidades de Surabaia e Yogyakarta (Bueno, 2000). No Cairo, outra grande metrópole subdesenvolvida, alvo da "modernização ocidental", também a metade da população vivia, em 1996, em condições informais. Evidentemente, os números da África, a extrema periferia esquecida da economia-mundo capitalista, são ainda mais assustadores: em Luanda, capital da Angola, $70 \%$ da população morava na informalidade. Em Adis Abeba, na Etiópia, eram 85\% (Bueno, 2000).

Outra característica da urbanização desigual é o exagerado ritmo de crescimento das periferias pobres em relação aos centros urbanizados. Enquanto a taxa média de crescimento anual das cidades brasileiras é de 1,93\%, o da periferia de São Paulo chega a 4,3\% ao ano (Instituto Cidadania, 2000). Em Deli, na Índia, a região urbanizada crescia 3,8\% ao ano, entre 1981 e 1991, enquanto as zo- nas rurais adjacentes à mancha metropolitana urbanizavam-se ao ritmo de 9,6\% ao ano (IRD, 1998). Em Bogotá, na Colômbia, de 1973 a 1985, os bairros centrais da cidade apresentaram taxas negativas de crescimento e os da periferia cresceram entre $7,5 \%$ e $12,5 \%$, no mesmo período.

\section{ENTRE A CIDADE E A BARBÁRIE}

Esse é, portanto, o cenário das grandes cidades subdesenvolvidas, no início do século XXI: um alto grau de pobreza, oriundo da natureza estruturalmente desequilibrada da industrialização e da urbanização periféricas. A preocupação de Prado Jr. estava certa, e hoje é patente a impossibilidade de reintegrar o contingente excessivo de mão-de-obra nos grandes centros urbanos, o que agrava inexoravelmente o quadro social. É nesse contexto que a globalização tenta imprimir suas características modernizadoras, exacerbando o quadro de antagonismo explicitado anteriormente, pois, no contexto urbano, a contradição estrutural das economias de desenvolvimento desigual e combinado se traduz pela incompatibilidade entre os bairros "globalizados" da cidade formal e os assentamentos ditos "subnormais", que configuram a tipologia majoritária da cidade real, nas zonas periféricas abandonadas pelo capital e pelo poder público.

Como mostraram os números da exclusão urbana apresentados anteriormente, há hoje mais pobres do que ricos em muitas metrópoles do Terceiro Mundo. Isso provoca, obviamente, uma inversão no conceito "do que é" a verdadeira cidade, pois as elites estão na verdade cada vez mais "sitiadas" em um mar de pobreza. Nunca as classes dominantes se sentiram tão ameaçadas. Não é à toa, portanto, que a grande imprensa brasileira - tradicionalmente representante dos interesses de nossas elites - use repetidamente termos como "centro invadido", ou "cidade sitiada" (Veja, 2001) para expressar o sentimento de que a verdadeira cidade, a que "vale", é apenas a cidade formal que essas elites ocupam. Ao invés de perceberem no crescimento inexorável da pobreza a preocupante e inaceitável mudança do perfil socioeconômico geral dos habitantes, as elites apenas se preocupam com uma invasão indesejada da "sua" cidade. A recusa em perceber que essa cidade já não é mais representativa da cidade real verifica-se tanto na constante busca de segurança e conforto em bairrosfortalezas de altíssimo padrão - como Alphaville, em São Paulo, Muang Thong Thani, em Bangcoc, e Nordelta, em Buenos Aires - quanto na reação de indignação em face 
dos níveis insustentáveis de violência urbana gerados pelo chamado "apartheid social urbano".

Talvez se possa então tomar emprestado, para aplicálo ao contexto urbano, o raciocínio exposto por Sampaio Jr. (1999a) para a particular situação do capitalismo brasileiro no pós-guerra: enquanto as cidades fordistas periféricas mantiveram-se, nas últimas décadas, sob controle da burguesia, apesar do alto grau de desigualdade e pobreza nas suas franjas periféricas, mantiveram sob relativo controle a matriz espacial e temporal do desenvolvimento urbano. As cidades eram o locus político privilegiado para o exercício da onipotência das classes dominantes, independentemente da pobreza que se fazia crescente. ${ }^{9}$ A situação social das cidades, no final da década de 90, entretanto, transformou essa contradição em aberto antagonismo. A burguesia parece ter perdido definitivamente o controle sobre o crescimento urbano desigual, e cada vez mais faz-se necessária uma opção mais radical entre a manutenção de um status-quo urbano, em que as estruturas das relações sociais, econômicas e políticas chegaram a níveis intoleráveis, e a adoção de medidas que abalem radicalmente essas estruturas no sentido da construção de uma cidadania baseada em princípios de eqüidade social. No caso das cidades brasileiras, assim como certamente em muitas metrópoles subdesenvolvidas, pode-se dizer que se vive, hoje em dia, uma situação limítrofe entre "a cidade e a barbárie".

A cidade subdesenvolvida expressa a marginalidade social em países que combinam o atraso com o moderno. Seu problema é portanto o mesmo da sociedade subdesenvolvida: a subordinação absoluta à lógica dos negócios, por meio da histórica superexploração do trabalho e superdepredação do meio ambiente, que parecem ter chegado, na sociedade e nas cidades, a níveis intoleráveis. Entretanto, as ações de imposição do capitalismo hegemônico, pelo novo paradigma da globalização, e as novas matrizes de planejamento urbano que as acompanham, parecem apenas reforçar essa situação.

\section{PLANEJAMENTO ESTRATÉGICO E SUBDESENVOLVIMENTO}

Se, por um lado, as políticas liberais nos moldes do conhecido Consenso de Washington, ${ }^{10}$ apresentadas ao Terceiro Mundo como uma tábua de salvação para a crise dos anos 80 , promoveram certa dinamização econômica ligada ao terciário avançado e às indústrias de ponta (no centro dos novos paradigmas econômicos da globaliza- ção), por outro, pouco resolveram e até acentuaram a desigualdade social, fato hoje admitido até pelo Banco Mundial (Folha de S.Paulo, 16/09/99). A Cepal avalia que as reformas liberais tiveram "um efeito surpreendentemente pequeno" no crescimento, no emprego e na eqüidade, em nível agregado (Stallings e Peres, 2000). O modelo preconizado não vinha com a advertência ${ }^{11}$ de que a possível modernização decorrente da globalização nos países subdesenvolvidos só beneficiaria a poucos e que, pelo contrário, o alto grau de exclusão desse processo iria sim deixar de fora grandes parcelas das populações envolvidas (Fiori, 1997).

Mesmo que exista hoje forte desconfiança sobre os efeitos dos ajustes estruturais de cunho liberal impetrados por vários países subdesenvolvidos, seus correspondentes no âmbito das políticas urbanas continuam sendo apresentados como mais atuais do que nunca (Maricato, Fix e Ferreira, 1999). Esse novo instrumental técnico de gestão das cidades, um "novo planejamento" que ficou conhecido como Planejamento Estratégico (PE), adaptado às características de flexibilidade e dinamismo da economia globalizada, contrapõe-se ao planejamento funcionalista modernista e busca referências em parâmetros ligados à gestão empresarial. A principal característica do PE é a de que ele não traz uma resposta, em termos de políticas públicas, ao impasse antagônico existente nas cidades subdesenvolvidas. Pelo contrário, parece acirrar ainda mais tal anacronismo.

O Planejamento Estratégico pauta-se pela visão de que a única maneira de se pensar o futuro das cidades é inserilas numa rede de "cidades-globais", na qual a problemática central deve ser a competitividade urbana (Vainer, 2000): “As agências multilaterais e seus ideólogos já desenharam a cidade ideal do limiar do século XXI: é a cidade produtiva e competitiva, globalizada, conectada a redes internacionais de cidades e de negócios. Concebida e pensada como empresa que se move num ambiente global competitivo, o governo desta cidade se espelha no 'governo' da empresa: gestão empresarial, marketing agressivo, centralização das decisões, pragmatismo, flexibilidade, entre outras, seriam as virtudes das quais dependeria cada cidade para aproveitar as oportunidades e fazer valer suas vantagens competitivas no mercado de localização urbana". ${ }^{12}$

A idéia, portanto, é a de que a cidade globalizada encontra mais chances de sobrevivência quanto mais souber se inserir na competição pela atração de investimentos e de sedes de grandes empresas transnacionais, quanto mais 
investir nos avançados sistemas de informação e comunicação, na modernização de sua infra-estrutura, no fortalecimento do "terciário avançado" e em canais de conexão com o capital financeiro internacional, supostamente capaz de dar nova vida às áreas urbanas "degradadas". O arcabouço técnico desse "novo" planejamento divide as ações de intervenção no espaço urbano em várias escalas, todas elas vinculadas às comunicações ou às atividades conectadas à economia globalizada: teleportos, centros empresariais, espaços para feiras e congressos, parques tecnológicos, aeroportos, hotéis, operações de embelezamento e modernização dos espaços públicos, etc. (Borja e Castells, 1997b).

A melhor ilustração dos resultados desse "novo" planejamento urbano está na descrição da "bolha especulativa" de Bangcoc, feita no início deste artigo. Uma pujante renovação imobiliária das áreas mais nobres, resultante da articulação entre os atores locais essenciais para a dinamização econômica urbana - a saber, os empreendedores imobiliários, as elites fundiárias, o poder público ${ }^{13}$ e os investidores, sejam estes nacionais ou internacionais - em torno da construção de "consensos" para identificar as "possibilidades econômicas dos lugares" de forma que se tornem atraentes para os potenciais "compradores" da cidade, os investidores internacionais (Arantes et alii, 2000 e Vainer, 2000). Percebem-se facilmente o forte caráter empresarial da ação do PE e a ausência de preocupações com questões sociais mais urgentes, contrapondo-se à farta presença de termos como "valorização", "negócios", "visibilidade", "inserção na dinâmica econômica" e outros que remetem à nova função concorrencial das cidades. Neste cenário, a realidade social das metrópoles subdesenvolvidas parece ter sido simplesmente esquecida. Ocorre de fato que, mais uma vez, modelos técnico-teóricos de planejamento são importados de uma realidade que não é a da periferia, porém são implantados aqui como se fossem a chave para a caminhada "rumo ao Primeiro Mundo". A incompatibilidade entre essas receitas e a nossa realidade urbana levou Ermínia Maricato (2000) a cunhar o termo "as idéias fora do lugar e o lugar fora das idéias".

O modelo do Planejamento Estratégico, não obstante, vem sendo aplicado por diversos municípios na América Latina, geralmente promovido por grandes operações de marketing, como cabe a qualquer operação de cunho concorrencial. Assim, ficaram conhecidos por aqui os exemplos do Plano Estratégico da Cidade do Rio de Janeiro, ou ainda o plano de reurbanização do Eixo Tamanduatehy, promovido em Santo André-SP ${ }^{14}$. No caso do Rio,
Vainer (2000) mostra como se trata de uma "bem orquestrada farsa", montada para colocar em escanteio as reivindicações populares e dar espaço aos interesses dos empreendedores e a um agressivo marketing de criação de falsos consensos que a legitimassem. Tudo para validar "projetos caros aos grupos dominantes da cidade", que permitiriam tornar a cidade competitiva e vendável à dinâmica do capital internacional. Na Argentina, o Planejamento Estratégico vem sendo implementado oficialmente em várias cidades, com destaque para Córdoba e Bahia Blanca.

\section{AS "ILHAS DE PRIMEIRO MUNDO"}

As políticas públicas afinadas com o novo cenário econômico excludente da globalização promoveram nos anos 90 - e o Planejamento Estratégico se insere nesse processo - a desregulamentação e flexibilização das normas urbanísticas e a fragmentação urbana (Clichevsky, 2000), em contraposição ao centralismo funcionalista e regulador do paradigma anterior (Planejamento Modernista). Assim como as políticas de ajuste neoliberal abriram as portas para a entrada do capital globalizado interessado nas importantes parcelas de consumidores altamente capitalizados dos países periféricos (devido ao alto grau de concentração da renda), a desregulação urbana favoreceu a ação da articulação "empreendedores imobiliários/proprietários fundiários/grande capital/poder público", que viram nas parcelas abastadas das sociedades periféricas e nas empresas transnacionais atuantes nesses mercados uma grande oportunidade de negócios imobiliários. Por isso, repetem-se pelo mundo afora os exemplos de produção de espaços de alto poder aquisitivo, verdadeiras "ilhas de Primeiro-Mundo" dentro do mar de pobreza das metrópoles subdesenvolvidas. Pode-se dizer que a produção do espaço nas cidades antagônicas da periferia da globalização segue cada vez mais um parâmetro de segregação social, em que as elites dominantes determinam sua conformação, excluindo abertamente as camadas populares, num fenômeno que por sinal não é propriamente novo, como já demonstrou Villaça (1999a). Essas "ilhas" podem ter funções ou características diferentes, podendo ser bairros residenciais, zonas de negócios voltadas ao terciário avançado, ou ainda áreas mais centrais “degradadas" e recuperadas para novos usos residencial e comercial voltados para as elites urbanas (a chamada gentrificação). Todas elas, entretanto, caracterizam-se pelo alto volume de investimentos privados e públicos, pelas modernas tecno- 
logias empregadas, pela qualidade da infra-estrutura urbana disponibilizada e pelo alto poder aquisitivo de seus usuários. Muitas são fruto de articulações encabeçadas pela ação decisiva de arquitetos-empreendedores ${ }^{15}$ (Arantes, 2000), interessados na criação de promissoras oportunidades para o grande capital (às vezes de maneira artificial, como em Bangcoc).

Já foram citados os exemplos dos bairros residenciais de Muang Thong Thani, em Bangcoc, Parque Panamby, em São Paulo, e Nordelat, em Buenos Aires. O modelo de gentrificação de áreas centrais, iniciado nos países industrializados nas conhecidas operações urbanas de Battery Park, em Nova York, e de London Docklands, em Londres (Nobre, 2000), passou a ser aplicado na periferia como receita de sucesso para dar "nova vida" (na verdade, vida das elites) a bairros centrais abandonados por causa da nova dinâmica da economia globalizada (mais uma vez, as "idéias fora do lugar"). Um dos exemplos mais sintomáticos é o de Puerto Madero, em Buenos Aires. Em São Paulo, embora deva agora contar - felizmente - com a enérgica oposição de grupos organizados da sociedade civil, como o Fórum Centro Vivo, já é grande a articulação entre empresários, investidores, poder público estadual, arquitetos e empreendedores imobiliários para a promoção de uma "revitalização" do centro nos moldes da gentrificação urbana, para fazer com que ele volte a ser "visto" pelo grande capital. No âmbito empresarial, a Operação Urbana Faria Lima, em São Paulo, vem promovendo a criação de uma "nova centralidade" de negócios e comércio, no eixo de crescimento sudoeste da cidade, ao longo da calha do rio Pinheiros (Nobre, 2000).

Assim, ao crescimento acelerado das periferias pobres e à presença de áreas centrais abandonadas pelas elites, se contrapõem zonas de crescimento exclusivo das classes dominantes, que conformam metrópoles divididas entre a cidade formal, alvo de todos os investimentos imobiliários e da ação e investimentos do poder público, e a informal, esquecida por ambos ${ }^{16}$ (Maricato, 1996). Os exemplos no Brasil nos são familiares, como a Zona Sul do Rio de Janeiro, ou a região sudoeste de São Paulo. No resto do mundo, não é diferente: é o bairro de Colaba, em Bombain, a região sul e o distrito de Nova Delhi, em Deli, Índia, e assim por diante.

O aspecto mais importante a ser destacado é que essa lógica vem pressupondo uma forte participação do poder público em sua promoção, seja por estar este representando os interesses dominantes, seja por estar certo que promove de alguma maneira a "modernização" da cidade.
Comprometem-se, em áreas privilegiadas, altos valores do orçamento na produção de infra-estrutura urbana, principalmente viária, compatível com as exigências das "ilhas de modernidade", em detrimento dos investimentos maciços urgentemente necessários na cidade informal, o que ressalta o alto caráter de exclusão desse processo. Assim, Maricato (2000:141) mostra que o governo paulistano, em 1998, gastou, em 11 obras viárias, "a incrível soma de US\$ 7 bilhões, aproximadamente, comprometendo a cidade com dívidas que iriam tornar inviáveis até mesmo os serviços básicos da gestão seguinte. Dessas 11 megaobras, apenas duas não estavam no interior ou próximas da região que concentra os bairros de mais alta renda de São Paulo. Aparentemente tratou-se da estratégia de construir uma 'ilha de Primeiro Mundo', com condições para abrigar a São Paulo, cidade mundial. No mesmo período o governo municipal descumpriu a lei que obrigava o município a investir 30\% do orçamento na Educação".

\section{SÃO PAULO, CIDADE GLOBAL?}

Se a relação entre os modelos econômicos de ajuste estrutural adotados nacionalmente e a não-melhoria subseqüente do quadro de pobreza, em especial nas cidades, parece agora mais clara, varia de país para país a eventual relação direta entre o capital financeiro globalizado e o aquecimento imobiliário nas grandes cidades com potencial para "cidades-globais". Por exemplo, o alto grau de comprometimento direto do grande capital internacional nas operações imobiliárias especulativas na Tailândia não encontra semelhanças (ainda?) no Brasil. Segundo Fix (no prelo), os investidores mais proeminentes nos megaprojetos imobiliários brasileiros ligados ao terciário avançado (como na região da Av. Luiz Carlos Berrini, em São Paulo) são fundos de pensão nacionais. Entretanto, mesmo que não sejam capitais diretamente ligados ao mercado internacional, é importante ressaltar que são de caráter financeiro e especulativo, ou seja, fortemente inseridos na dinâmica financeira do capitalismo internacional globalizado. Também é sintomática a paulatina entrada no mercado brasileiro de grandes grupos estrangeiros de promoção imobiliária, como o caso da Richard Ellis, uma das principais promotoras na área da Av. Luiz Carlos Berrini. Nobre (2000:144) destaca a ação desses atores, na cidade de São Paulo: "os investidores preferidos para cooptação dos promotores foram os fundos de pensão(...). Entre 1990 e 1998, os investimentos dos fundos de pensão no mercado imobiliário passaram de 2 para aproximadamente US $\$ 8$ bilhões 
(...). A associação dos promotores imobiliários com esses investidores possibilitou a construção de uma grande quantidade de edifícios modernos (...) cujos locatários preferidos foram as grandes corporações multinacionais".

Por esse critério, entende-se a argumentação daqueles que se empenham em definir a cidade de São Paulo como uma "cidade-global". Não é, entretanto, o critério mais animador, haja vista o resultado desastroso da implicação do capital financeiro internacional no mercado imobiliário de Bangcoc. Nobre (2000) mostra como os megaprojetos servem apenas como uma forma de atrair investimentos através de um desenho urbano que agrade às grandes corporações e às elites. Pautando-se pelo exemplo dos megaprojetos executados na década de 80 , nos EUA e em Londres, o autor mostra como isso, no entanto, aumenta o potencial de risco dos investimentos imobiliários: "a expansão do mercado imobiliário nessa década ocorreu através da criação artificial de demanda, pois os edifícios foram construídos por razões financeiras (maiores taxas de retorno), e não por necessidades reais do mercado, levando à desvalorização do estoque construído e ao crescimento das taxas de vacância nos edifícios antigos. (...) Em outras palavras, o projeto autojustificase. Ele não responde nem às forças do mercado, nem às necessidades identificáveis. E cria demanda artificialmente. (...) A quebra da bolsa de valores na Segunda-Feira Negra (19 de outubro de 1987) pôs fim ao período de crescimento econômico, levando à perda de empregos no setor que mais se beneficiou com a desregulamentação econômica. Londres e Nova York perderam cada uma aproximadamente 100 mil empregos no setor financeiro (Fainstein, 1994). O mercado imobiliário foi diretamente afetado pelo grande aumento da vacância dos edifícios comerciais, que chegou a duplicar, alcançando $20 \%$ do estoque construído" (Nobre, 2000:127-128).

A fragilidade da relação entre investimentos financeiros e imobiliários é patente, e a crise em Bangcoc evidenciou isso mais do que nunca. É interessante notar que os edifícios mais modernos de São Paulo, na "nova centralidade" das Avenidas Berrini e Águas Espraiadas, são ocupados por empresas em regime de locação (Nobre, 2000). Em situações de instabilidade econômica mais séria, que podem ocorrer, como se sabe, a qualquer hora, essas empresas reorganizam sua estrutura física para enxugar custos, substituindo, rapidamente, os custosos "edifícios inteligentes" por soluções mais baratas, como escritórios junto às fábricas, ou aluguel de edifícios mais simples, aumentando de forma inesperada a taxa de va- cância e comprometendo o retorno dos investimentos imobiliários. Se o alto risco dos investimentos imobiliários já provocou crises não só em Bangcoc, mas também em países centrais como os EUA e a Inglaterra, o que dizer dos riscos eventuais em uma economia que se encontra em alto grau de instabilidade como a brasileira (Sampaio Jr., 1999a)? São Paulo, com seus cerca de 6 milhões de excluídos, teria fôlego financeiro e econômico suficiente, no restrito círculo de suas elites sitiadas, para garantir o sucesso de um boom econômico promovido diretamente pelo capital especulativo internacional?

Outra argumentação típica daqueles que pretendem enfaticamente atribuir à cidade de São Paulo o título de "cidade-global" é a que aponta para um processo de substituição das atividades industriais características do fordismo por novas atividades de caráter globalizado, em geral ligadas ao terciário avançado. Embora seja verdade que a cidade concentra grande volume de atividades desse setor (o que não é, aliás, um fato novo nem exclusivo da era da globalização), é interessante observar os resultados de pesquisa feita pela Secretaria de Planejamento, que, após classificar as atividades econômicas da cidade em "globais" ou "não-globais", constatou que apenas 7,2\% dos estabelecimentos se enquadram em "atividades mais diretamente ligadas ao que se convencionou chamar de globalização" (PMSP, 2001:29).

Também argumenta-se a existência de uma fuga maciça de indústrias para centros mais distantes, devido ao alto custo de manutenção de empresas na cidade e às facilidades de gestão empresarial descentralizada propiciadas pela tecnologia de comunicação, em um processo de desconcentração industrial. Embora seja este um fenômeno verdadeiro, ele ainda ocorre em proporções muito relativas, bem menos importantes do que o propagado. Dados da Fundação Seade mostram que a Região Metropolitana ainda é responsável por $60,4 \%$ de todo o valor adicionado gerado pela indústria paulista e por $56,8 \%$ do pessoal ocupado no Estado (Fundação Seade, 2000).

Além disso, o aumento das atividades terciárias tem com certeza relação com a expansão dos setores do "terciário avançado" ligados à economia globalizada, mas é sobretudo a queda do nível de emprego industrial, conseqüência do impacto destrutivo da globalização sobre o parque industrial brasileiro, que determinou uma migração de parte desses trabalhadores desempregados para o setor terciário, ou ainda para o setor informal. Dados da Prefeitura de São Paulo mostram um aumento significativo do desemprego em São Paulo, entre 1988 e 1998, 
crescendo de $8,2 \%$ para $17 \%$ (PMSP, 2001) devido à diminuição da atividade industrial, que passou de $29,1 \%$ para $17,8 \%$ no mesmo período. Também se transferiram empregos para o setor de serviços, ainda que em grande parte em atividades não tão "globalizadas", como serviços domésticos e pequeno comércio. Porém, o aumento desse setor, entre 1988 e 1998, portanto exatamente no período de intensificação dos paradigmas econômicos da globalização, não foi tão significativo, e principalmente partiu de um valor já bastante alto em 1988: de 51,3\% para $62,4 \%$. O que impressiona, isto sim, é que a recessão econômica fez com que a economia informal crescesse enormemente, de tal forma que o emprego assalariado com registro representava, em 1998 , apenas $40,5 \%$ das ocupações (PMSP, 2001).

Não se pretende aqui negar o caráter globalizado de um importante número de atividades econômicas desenvolvidas hoje em São Paulo, em especial na chamada "nova centralidade" das Avenidas Faria Lima, Berrini e Águas Espraiadas. Tampouco se quer negar que a cidade desempenhe de fato um papel de destaque na nossa inserção na economia globalizada. O questionamento que se faz aqui diz respeito ao grau de importância que se dá a essa inserção - e portanto ao papel global da cidade e à crença de que ela seja uma via eficaz para a "modernização" do país, em moldes que não sejam os dos interesses das burguesias nacionais, mas sim os do conjunto da sociedade. Parece que a ênfase dada por pesquisadores e profissionais de planejamento ao estudo sobre a maneira e a posição com que a metrópole se insere na rede das cidades globais reflete uma matriz teórica equivocada, pois importada dos países centrais, e que não responde aos desafios próprios da nossa realidade. Uma matriz, aliás, que não se adapta em nenhuma metrópole de países da economia dependente. É um caso típico de "idéias fora do lugar" (Maricato, 2000).

Qual é, então, a "modernidade" que queremos? A da possibilidade de autodeterminação da nação nos moldes da democracia e da eqüidade econômica e social. Porém, o modelo de ajuste estrutural neoliberal e sua vertente urbanística do planejamento estratégico só servem, como visto, para produzir mais exclusão e garantir a "entrada no Primeiro Mundo" apenas de alguns privilegiados. Podese então perguntar: para a solução dos problemas estruturais que impedem o desenvolvimento efetivamente includente e a construção de uma nação que controle o seu próprio destino, qual a vantagem, na ponta do lápis, em São Paulo ser uma cidade-global?

\section{NOTAS}

Agradeço a Helena Menna Barreto, da FAUUSP, e Alfredo Calcagno, da Cepal, pela ajuda na obtenção de dados essenciais à redação deste artigo.

1. Sassen, Borja, Castells e muitos outros autores que defendem a idéia de que a economia globalizada se organiza nessa "rede mundial de cidades" medem o grau de "globalização" de uma metrópole através de dados como o número de sedes de empresas transnacionais, a importância de suas bolsas de valores, o grau de informatização e de capacidade informacional do parque imobiliário, o número de equipamentos destinados aos negócios (hotéis, business-centres...), etc. Ver a respeito Arantes et alii (2000), Maricato (2000), Vainer (2000) e Ferreira (2000).

2. À guisa de comparação, em 1996, um ano em que o mercado esteve especialmente aquecido, a média de lançamentos de habitações no mercado formal na cidade de São Paulo, segundo a Embraesp, foi de 30 mil unidades.

3. Aceitando-se, é claro, as variações devidas às especificidades históricas e culturais tão diferentes de cada país. Ver, por exemplo, Amin (1991).

4. Nos termos propostos por Braudel (1978) e Wallerstein (1994).

5. As agências multilaterais criaram vários rótulos para diferenciar países como Brasil, México, Índia ou Paquistão, considerados com grande potencial de "entrar" na economia globalizada: economias em desenvolvimento, semi-industrializadas, emergentes, etc. Neste trabalho, adotou-se a definição "países subdesenvolvidos" para identificar tanto estes quanto todos os outros países da periferia, já que nenhum deles deixa de apresentar níveis inadmissíveis e generalizados de pobreza.

6. Taxas de urbanização na Malásia $-52,1 \%$, Nigéria - 37,7\% e Índia $-26,3 \%$ (World Bank, 1995).

7. São elas, em ordem de tamanho decrescente: Cidade do México, São Paulo, Seul, Moscou, Bombain, Calcutá e Buenos Aires-La Plata (Lefebvre, 1992).

8. O que dizer daqueles que dispõem de 1,5 dólar/dia, e que estatisticamente não são mais, portanto, considerados pobres.

9. Ao contrário, a pobreza tornou-se até politicamente interessante ao permitir a corrupção eleitoral através da compra de votos, a manipulação eleitoral, etc.

10. O documento completo - embora por natureza extremamente sucinta, como devem ser as cartilhas - do Consenso de Washington pode ser lido em Williamson (1994).

11. Não foi, entretanto, por falta de advertências por parte de um grande número de intelectuais brasileiros, entre os quais destacam-se José Luis Fiori, Maria da Conceição Tavares, Francisco de Oliveira, Otília Arantes, Ermínia Maricato, Plinio Sampaio Jr., e muitos outros, que o Brasil adotou a cartilha do Consenso de Washington.

12. Manifesto de lançamento da idéia de uma Rede Brasileira de Planejadores pela Justiça Social, Porto Alegre, 27 de janeiro de 2001.

13. Nas muitas vezes em que este representa os interesses dos setores dominantes, o que não é incomum em países subdesenvolvidos nos quais as prioridades das políticas públicas são muito freqüentemente invertidas a favor desses setores e em detrimento do bem geral e da homogeneização social.

14. Ainda que não definido como tal pela prefeitura daquela cidade.

15. Em São Paulo, a figura do arquiteto-empreendedor é bastante familiar: Carlos Bratke (Av. Luiz Carlos Berrini), Julio Neves (Av. Faria Lima) e Ruy Othake são alguns dos exemplos mais conhecidos. Nos países industrializados, as grandes operações de promoção urbanísticas sempre envolvem um seleto grupo de grandes e festejados escritórios de arquitetura, até como forma de garantir um markenting urbano mais eficaz.

16. Uma rara exceção à regra é Joanesburgo, na África do Sul, que por motivos próprios à dinâmica do "fim" do apartheid racial naquele país, foi inteiramente ocupada pela população negra e pobre após a elite branca ter decidido abandoná-la por completo.

\section{REFERÊNCIAS BIBLIOGRÁFICAS}

AMIN, S. L'empire du chaos. Paris, L'Harmattan, 1991.

ARANTES, O.B.; MARICATO, E. e VAINER, C. O pensamento único das $\mathrm{ci}$ dades: desmanchando consensos. Petrópolis, Vozes, 2000 (Coleção Zero à Esquerda).

ARRIAGADA, C. Pobreza en América Latina: nuevos escenarios y desfios de politicas para el hábitat urbano. Santiago do Chile, Cepal/Eclac - División 
de Medio Mabiente y Assentamientos Humanos, Série Medio Ambiente y Desarrollo, n.27, out. de 2000.

BORJA, J. e CASTELLS, M. Local \& global: management of cities in the information age. Londres, UNCHS (Habitat/ONU) e Earthscan Publications, 1997a.

"Planes estratégicos y proyectos metropolitanos". Cadernos IPPUR. Rio de Janeiro, UFRJ, Ano XI, n. 1 e 2, 1997b.

BRAUDEL, F. Escritos sobre a história. São Paulo, Editora Perspectiva, 1978.

BUENO, L.M. de M. Projeto e favela: metodologia para projetos de urbanização. Tese de Doutorado. São Paulo, Faculdade de Arquitetura e Urbanismo da Universidade de São Paulo, 2000.

CASTRO, M. e RIOFRÍO, G. "La regularización de las barriadas: el caso de Villa El Salvador (Perú)”. In. AZUELA, A. e FRANÇOIS, T. (orgs.). El acesso de los pobres al suelo urbano. México, Centro de Estúdios Mexicanos y Centroamericanos, Universidad Autónoma de México, Instituto de Investigaciones Sociales, Programa de Estudios sobre la Ciudad, 1997.

CEPAL. Panorama Social de América Latina 1999-2000. Santiago do Chile, Comissão econômica para a América Latina e o Caribe - ONU, 2000a.

.From rapid urbanization to the consolidation of human settlements in Latin America and the Caribbean: a territorial perspective. Santiago do Chile, Comissão Econômica para a América Latina e o Caribe - ONU, 2000b.

CHARMES, E. "La nouvelle bulle a éclaté en Thaïlande". Etudes Foncières. Paris, n.81, Adef - Association des Etudes Foncières, Inverno de 1998.

CLICHEVSKY, N. Informalidad y segregación urbana en América Latina: una aproximación. Santiago do Chile, Cepal/Eclac-División de Medio Mabiente y Assentamientos Humanos, Série Medio Ambiente y Desarrollo, n.28, out. de 2000 .

FAINSTEIN, S. The city builders: property, politics and planning in London and New York. Oxford, Blackwell Publishers, 1994.

FERREIRA, J.S.W. São Paulo metrópole subdesenvolvida: para que(m) serve a globalização?. São Paulo, FAUUSP, 2000, mimeo.

FIORI, J.L. Os moedeiros falsos. Petrópolis, Vozes, 1997.

FIX, M. Parceiros da exclusão: duas histórias da construção de uma nova cidade em São Paulo. São Paulo, Editora Boitempo, no prelo.

FOLHA DE S.PAULO. “Abertura não reduz pobreza, diz Bird”, São Paulo, Segundo Caderno, 16/09/99, p.1.

FPH. Politiques urbaines et lutte contre la pauvreté. Paris, Documents de Travail des Editions Charles Leopold Mayer, n.96, 1997.

FUNDAÇÃO SEADE/Governo do Estado de São Paulo. Cadernos do Fórum São Paulo Século XXI. São Paulo,Tomo III, Caderno 11, Diário Oficial do Estado de São Paulo, volume 110, n.109, jun. 2000.

IBASE e outras ONGs. Observatório da Cidadania: monitorando o desenvolvimento-Social Watch. Montevideo, n.1, Uruguai, Instituto del Tercer Mundo, 1997.

INSTITUTO CIDADANIA. Projeto Moradia. São Paulo, 2000.

IRD. Atelier International "Metropoles en mouvement". Programme Ville/Réseau Socio-Economique de l'Habitat. Paris, IRD/CNRS, dezembro 1998.

LEFEBVRE, S. Mondialisation et urbanisation:l'evolution demografique d'un phenomène urbain. Montréal, Canada, paper INRS-Urbanisation- UQAM, 1992.
LIPIETZ, A. Mirages et miracles: problèmes de l'industrialisation dans le TiersMonde. Paris, La découverte, 1985.

LUCIANO, F. "Regularización de assentamientos irregulares en Córdoba". In. AZUELA, A. e FRANÇOIS, T. (orgs.). El acesso de los pobres al suelo urbano. México, Centro de Estúdios Mexicanos y Centroamericanos, Universidad Autónoma de México, Instituto de Investigaciones Sociales, Programa de Estudios sobre la Ciudad, 1997.

MARICATO, E. Metrópole na periferia do capitalismo. São Paulo, Hucitec/Série Estudos Urbanos, 1996.

"Planejamento urbano no Brasil: as idéias fora do lugar e o lugar fora das idéias". In: ARANTES, O.B.; MARICATO, E. e VAINER, C. Op.cit., 2000.

MARICATO, E.; FIX, M. e FERREIRA, J.S.W. "Encontro com a Planners Network: planejadores urbanos e justiça social". In: FAUUSP. Informativo FAUUSP, São Paulo, Ano 1, n.7, dez. de 1999.

NOBRE, E. C. Reestruturação econômica e território: expansão recente do terciário na marginal do rio Pinheiros. Tese de Doutorado. São Paulo, FAUUSP, ago. 2000

PMSP. Globalização e desenvolvimento urbano. São Paulo, PMSP/Sempla, 2001.

SAMPAIO Jr., P.A. Entre a nação e a barbárie: os dilemas do capitalismo dependente. Petrópolis, Vozes, 1999a.

“O impasse da 'formação nacional'”. In: FIORI, J.L. (org.). Estados e moedas no desenvolvimento das nações. Petrópolis, Vozes, 1999b (Coleção Zero à Esquerda).

"Origem e desdobramento da crise da teoria do desenvolvimento na América Latina”. São Paulo em Perspectiva. São Paulo, Fundação Seade, v.13, n.1-2, jan.-jun. 1999c.

SASSEN, S. La ville globale: New York, London, Tokyo. Paris, Descartes et Cie, 1996 (Collection Les Urbanités).

STALLINGS, B. e PERES, W. Crescimiento, empleo y equidad: el impacto de las reformas econômicas en América Latina. Santiago de Chile, Cepal/Fondo de Cultura Económica, 2000.

VAINER, C. "Pátria, empresa e mercadoria: notas sobre a estratégia discursiva do planejamento estratégico". In: ARANTES, O.B.; MARICATO, E. e VAINER, C. Op.cit., 2000.

VEJA. São Paulo, 22/01/2001.

VILLAÇA, F. "Efeitos do espaço sobre o social na metrópole brasileira". In: SOUZA, M.A.A. de et alii. Metrópole e globalização. São Paulo, Cedesp, 1999a.

"Uma contribuição para a história do planejamento urbano no Brasil”. In: DEÁK, C. e SCHIFFER, S. O processo de urbanização no Brasil. São Paulo, Edusp/Fupam, 1999b.

WALLERSTEIN, I. "A cultura como campo de batalha ideológico do sistema mundial moderno". In FEATHERSTONE, M. (org.). Cultura global: nacionalismo, globalização e modernidade. Petrópolis, Vozes, 1994.

WILLIAMSON, J. (org.). The political economy of policy reform. Washington, Institute for International Economics, 1994.

WORLD BANK. Social Indicators of Development. Bank Book, Baltimore/London World and John Hopkins University Press, 1995. 